\title{
LA SIERRA DE ATAPUERCA DURANTE EL HOLOCENO: DATOS PREMILINARES SOBRE LAS OCUPACIONES DE LA EDAD DEL BRONCE EN LA CUEVA DE EL MIRADOR (IBEAS DE JUARROS, BURGOS)
}

\author{
THE SIERRA OF ATAPUERCA IN THE HOLOCENE: \\ PRELIMINARY DATA ON THE BRONZE AGE OCCUPATIONS IN EL MIRADOR CAVE \\ (IBEAS DE JUARROS, BURGOS)
}

\author{
JOSEP MARIA VERGÈS $(*)$ \\ ETHEL ALLUÉ $(*)$ \\ DIEGO E. ANGELUCCI $(* *)$ \\ ARTHUR CEBRIÀ $(*)$ \\ CARLOS DÍEZ (***) \\ MARTA FONTANALS $(*)$ \\ ANTONI MANYANÓS $(*)$ \\ SONSOLES MONTERO $(* * *)$ \\ SERGIO MORAL $(* * *)$ \\ MANUEL VAQUERO $(*)$ \\ JOSEP ZARAGOZA $(*)$
}

\section{RESUMEN}

Las excavaciones arqueológicas iniciadas en 1999 en la cueva de El Mirador de la sierra de Atapuerca han permitido documentar hasta el momento una sucesión estratigráfica holocena de unos 2,5 $\mathrm{m}$ de potencia, formada por niveles del Neolítico y de la Edad del Bronce. Los datos preliminares sobre las ocupaciones de la Edad del Bronce señalan el uso de la cueva como redil, zona de hábitat y espacio sepulcral. Durante su uso como redil se llevó a cabo la quema periódica del estiércol depositado en el interior del corral. Es la primera vez que dicha práctica se documenta en la Meseta y, en el ámbito europeo, en contexto geográfico continental. El uso como cueva sepulcral viene seña-

(*) Área de Prehistoria. Dpto. de Historia y Geografia. Universitat Rovira i Virgili. Unidad asociada al CSIC. Plaça Imperial Tarraco, 1. 43005 Tarragona. España. Correo electrónico: verges@prehistoria.urv.es

(**) Centro de Investigação em Paleoecologia Humana e Arqueociências, Instituto Português de Arqueología, Av. da Índia 136. P-1300-300 Lisboa. Portugal. Correo electrónico: diego@ipa.min-cultura.pt

(***) Área de Prehistoria. Dpto. de Ciencias Históricas y Geografía. Facultad de Humanidades y Educación. Universidad de Burgos. Villadiego s/n. 09001 Burgos. Correo electrónico: clomana@ubu.es

Recibido: 30-I-2002; aceptado: 4-III-2002. lado por la presencia de una inhumación colectiva. Ésta presenta evidencias de un ritual relacionado con el tratamiento de los cadáveres previo a su enterramiento. Cabe subrayar también la presencia de una hacha de bronce de rebordes en contexto estratigráfico.

\begin{abstract}
The paper presents data from the El Mirador cave, part of the Sierra de Atapuerca project. The data deriving from the first two stratigraphical excavation campaigns (1999 and 2000) are illustrated. A 2.5-m thick Holocene succession, containing Neolithic and Bronze Age occupations, was excavated and sampled using a multidisciplinary perspective. Preliminary data on the Bronze Age occupations indicate the utilization of the rock-shelter for various activities, among them animal stabling, habitation and burial. Animal stabling led to the accumulation of characteristic burnt layers, never seen before in the Meseta region or in wider European context. A Bronze Age collective burial showing evidence of pre-treatment of bodies before their deposition, and a stratified metal axe, were also found.
\end{abstract}




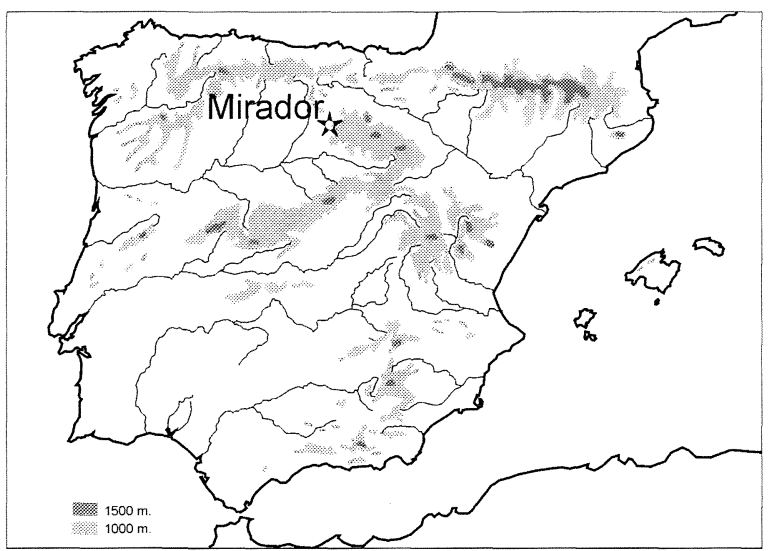

Fig. 1. Localización de la cueva de El Mirador.

Palabras clave: Sierra de Atapuerca. Cueva de El Mirador. Holoceno. Edad del Bronce. Niveles de corral. Inhumación colectiva.

Key words: Sierra de Atapuerca. El Mirador cave. Holocene. Bronze Age. Burnt layers. Collective burial.

\section{LA CUEVA DE EL MIRADOR}

La cueva de El Mirador se abre en la vertiente más meridional de la Sierra de Atapuerca (Ibeas de Juarros, Burgos), región ampliamente conocida en la bibliografía científica por sus importantes yacimientos arqueo-paleontológicos prehistóricos.

El yacimiento se sitúa a una altitud de $1033 \mathrm{~m}$ s.n.m. y sus coordenadas geográficas son: $42^{\circ} 20^{\prime}$ $58^{\prime \prime} \mathrm{N}, 03^{\circ} 30^{\prime} 33^{\prime \prime} \mathrm{O}$. Actualmente la cueva presenta la morfología de un abrigo debido al hundimiento de buena parte de su bóveda, aspecto muy similar, según los datos disponibles, al que ofrecía durante la Edad del Bronce. La cavidad tiene una boca de entrada de $23 \mathrm{~m}$ de anchura por 4 de altura, y unos $15 \mathrm{~m}$ de profundidad. La potencia de su relleno sedimentario se calcula en torno a los $12 \mathrm{~m}$, en base a los datos geofísicos disponibles actualmente. La cueva de El Mirador forma parte del sistema cárstico de la sierra de Atapuerca. Se trata probablemente de una antigua dolina colapsada que, tal y como indica la presencia de galerías en su interior, constituiría uno de los sumideros del sistema.

La primera intervención arqueológica de la que se tiene noticia en la cueva de El Mirador fue llevada a cabo por el Grupo Espeleológico Edelweis
(GEE) a principios de los 70, y consistió en la realización de una pequeña cata en la zona central de la cavidad. Entre otros objetos, se localizaron una punta de cobre de aletas y pedúnculo, varias lascas de sílex, un punzón de hueso y algunos fragmentos de cerámica, que en su momento fueron atribuidos al Eneolítico y a la Edad del Bronce (Osaba y Ruiz de Erenchun, 1978: 79). Dichos materiales se hallan depositados actualmente en los fondos del Museo de Burgos.

Posteriormente, el extremo norte de la cueva se vio afectado por la acción de excavadores clandestinos, lo cual conllevó la destrucción de la sucesión estratigráfica de dicha zona en una superficie de unos $20 \mathrm{~m}^{2}$, y en una potencia aproximada de un metro (1). Lamentablemente, no se dispone de ningún tipo de información sobre los materiales exhumados por estos furtivos. No obstante, tanto en las secciones como dispersos sobre el suelo del laminador, se observan numerosos restos óseos, la mayoría de ellos humanos, lo que parece indicar que dicha área fue utilizada como zona de inhumación colectiva, probablemente en algún momento de la Edad del Bronce.

Las campañas de excavaciones arqueológicas en la cueva de El Mirador realizadas en el marco del proyecto Autoecología Humana y Tecnología de los Pobladores Prehistóricos de la Sierra de Atapuerca comenzaron en 1999 y continúan aún en la actualidad. Paralelamente, en la campaña de 2000 se retomaron las intervenciones arqueológicas iniciadas en la década de los 70 por J. M. Apellániz en el Portalón de Cueva Mayor. Ambas excavaciones tienen como principal objetivo obtener datos sobre el poblamiento humano de la sierra durante el Pleistoceno Superior y el Holoceno que permitan completar la secuencia ocupacional conocida.

Los niveles correspondientes a la Edad del Bronce documentados en El Mirador, objeto de este artículo, se excavaron durante las campañas de 1999 y 2000. El principal objetivo de la intervención que se está llevando a cabo es la recogida de datos tanto arqueológicos como paleoambientales que permitan elaborar una secuencia de referencia del yacimiento. La información obtenida será utilizada

(1) Entre las principales agresiones sufridas por el yacimiento cabe destacar la protagonizada por varios miembros del Grupo Espeleológico Ramón y Cajal a principios de los años 80. El expolio llevado a cabo por estos individuos se centró en el extremo norte de la cueva, en la entrada e interior de un laminador que se abre en la misma dirección. Sorprendidos por componentes del GEE se cursó la correspondiente denuncia, lo que supuso la disolución definitiva de dicha agrupación. 
para planificar la futura realización de una excavación en extensión. Con este fin, en 1999 se inició un sondeo de $6 \mathrm{~m}^{2}$ en la zona central de la mitad oeste de la superficie de la cueva que aún conserva la bóveda. La selección de la zona donde debía situarse el sondeo se llevó a cabo basándonos en los resultados de una serie de prospecciones geofísicas que se realizaron en diferentes puntos de la superficie original de la cavidad. Se escogió la zona que mostró menor resistividad, donde, teóricamente, había menos probabilidades de encontrarse con alguno de los grandes bloques de piedra desprendidos de la bóveda de la cueva. Este lugar coincide con una de las zonas que no se vio afectada por la acción de los furtivos y que, por lo tanto, conserva la sucesión estratigráfica intacta.

\section{ESTRATIGRAFÍA}

La sucesión estratigráfica presenta una elevada variabilidad lateral y vertical, debido a la naturaleza y composición del sedimento, a la caída de bloques del techo, que delimitan áreas discretas, a la organización espacial antrópica y a las modificaciones sin- y postdeposicionales naturales (bioturbación) y antrópicas (pisoteo y excavación de estructuras). El conjunto de la sucesión estratigráfica posee un elevado componente antrópico, mientras que los procesos de sedimentación natural, así como los edafogénicos (sensu strictu), son escasos.

Los sedimentos exhiben, en su mayoría, textura limosa y tenor variable de arcilla, normalmente bajo, con esqueleto de piedras calizas de tamaño variable (hasta métricos), angulosas, sanas, con composición coherente con la roca de la cueva (caliza maciza, conglomerado calizo, detrito suelto de dicho conglomerado). Son normalmente blandos, de color oscuro y carbonatados. Los materiales procedentes de los procesos de combustión son abundantes, mientras que los artefactos son relativamente escasos. La estratificación es irregular, a veces discontinua, con buzamiento hacia el interior de la cavidad.

Debido a la mencionada variabilidad, se decidió nombrar y excavar la sucesión por conjuntos, diferenciando entre facies características en las unidades antropizadas. A continuación se presentan los datos de campo, preliminares por lo que se refiere a la dinámica de formación del relleno sedimentario, cuyo estudio debe ser pormenorizado a través de análisis de laboratorio. La sucesión estratigráfica explorada durante las campañas de 1999 y 2000 se organiza en seis conjuntos.

ATA-MIRI es el revuelto reciente, formado por brecha suelta en matriz limosa, cenicienta. En la zona interesada por el sondeo, este nivel estaba formado por una importante acumulación de materiales procedentes del cribado de sedimentos llevado a cabo por excavadores clandestinos.

ATA-MIR2 identifica el relleno de canales y cámaras de origen biológico (madrigueras actuales y subactuales de conejo y de zorro), que cortan los conjuntos MIR1, MIR3 y MIR4. Los caracteres sedimentarios varían según la posición, la profundidad y la unidad afectada por las cavidades, siendo medianamente limo arcilloso pardo, granular fino, orgánico, con ocasionales materiales arqueológicos y límites abruptos con las unidades colindantes.

ATA-MIR3 posee caracteres homogéneos. Es limo arcilloșo, con piedras, pardo amarillento, masivo y orgánico. Contiene pequeños carbones y agregados de ceniza, ésta también dispersa en la matriz (así como los objetos arqueológicos). El límite con MIR4 es neto, irregular, probablemente erosivo.

ATA-MIR4 está formado por sedimento de origen antrópico, orgánico, con acumulaciones características entre las que se han distinguido varias facies: $\mathbf{4 a}$ - limo arcilloso con piedras a veces modificadas por impacto térmico, masivo, frágil, con microcarbones y materiales comunes, concentrados o dispersos; $\boldsymbol{4} \boldsymbol{b}$ - ceniza pura, blanca, masiva, a veces con fina laminación plana, con carbones y pequeñas manchas amarillentas; $4 \boldsymbol{f}$ - como $4 \mathrm{~b}$, pero con fibras horizontales de orientación varia; $4 c$ acumulaciones de carbones; $\boldsymbol{4} \boldsymbol{d}$ - material orgánico, negro, formado por excrementos (coprolitos), a veces soldados unos a otros; $\boldsymbol{4} \boldsymbol{g}$ - limo gris claro, masivo, con abundante ceniza; $\mathbf{4 m}$ - ceniza parda cla$\mathrm{ra}$, a veces con estructura laminar, con pequeños carbones y fragmentos rubefactados; $\mathbf{4 o}$ - sedimento orgánico, negro, homogéneo, sin estructuras; $\mathbf{4 r}$ horizontes rubefactados por impacto térmico; $4 \boldsymbol{v}$ limo verde oliva con abundante ceniza dispersa; $4 t$ arcilla limosa, pardo grisáceo oscuro, con laminación plana débilmente ondulada, fibras vegetales horizontales, aportaciones detríticas y arqueológicas ocasionales.

Las facies forman secuencias rítmicas, muchas veces discontinuas y con límites abruptos. Se organizan en acumulaciones adosadas o en crestas y yacen horizontales o con inclinación baja, hacia 


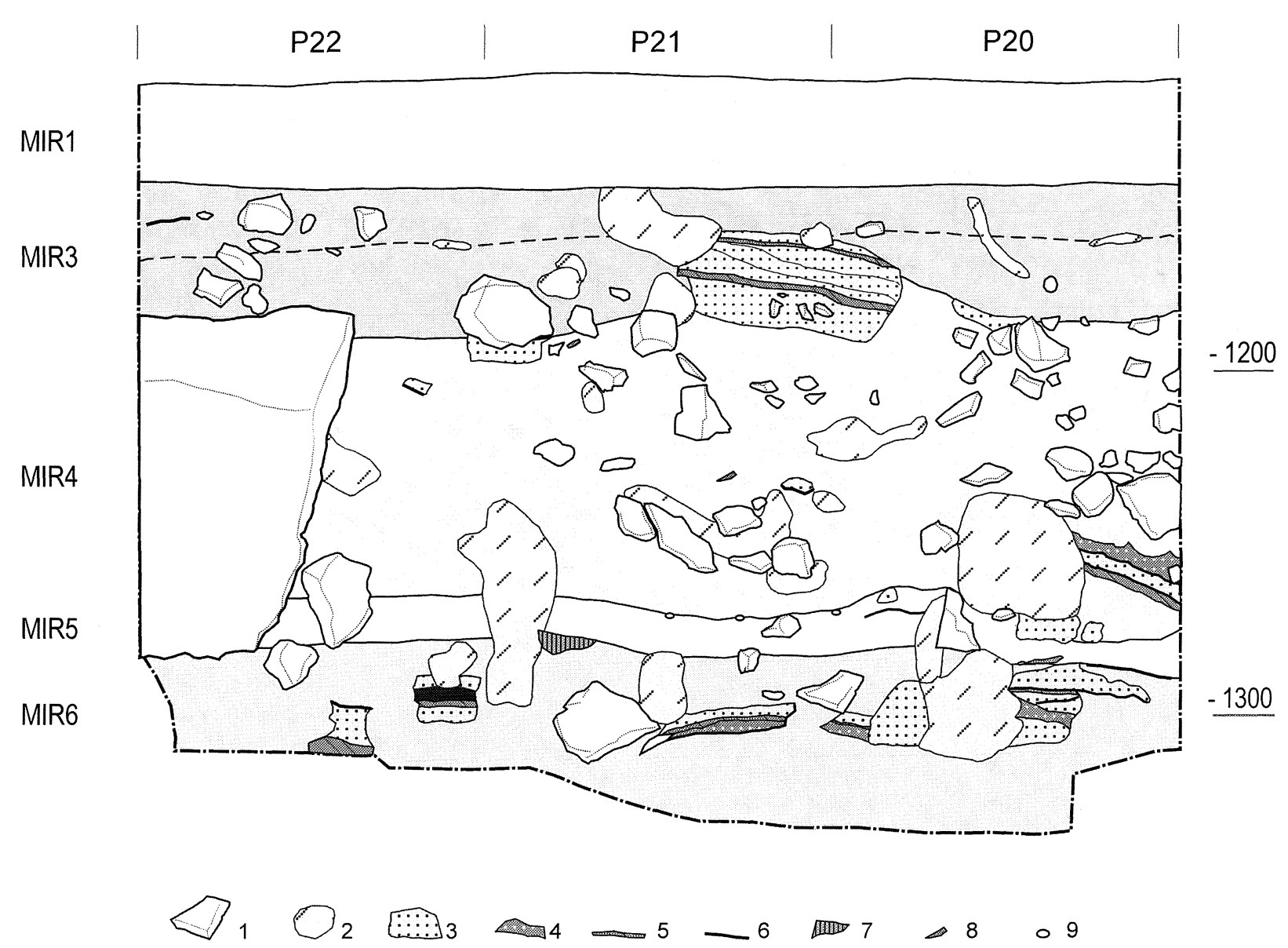

Fig. 2. El Mirador. Corte S del sondeo después de la excavación 2000: 1. fragmentos de caliza; 2. madrigueras; 3. acumulaciones de ceniza; 4. acumulaciones de ceniza y materia orgánica; 5 . sedimentos termoalterados; 6 . acumulaciones de carbón; 7. piezas líticas; 8. huesos; 9. egagrópilas.

$\mathrm{Nu}$ O. Las zanjas sindeposicionales (diferenciadas como 4P) las cortan aislando trozos de sedimento orgánico o también desplazándolos ligeramente.

Durante la excavación de MIR4 se documentó una pequeña fosa excavada en dicho conjunto, en la que se habían depositado restos humanos pertenecientes a varios individuos. La parte superior de dicha estructura se hallaba totalmente alterada por madrigueras de conejo, que rompían su continuidad e imposibilitaban contrastar si la deposición se llevó a cabo durante las ocupaciones de MIR4 o, posteriormente, durante las del conjunto MIR3. De forma provisional, y dado que la excavación de la fosa sólo se ha podido documentar en el conjunto MIR4, la acumulación de restos humanos se ha adscrito a esta unidad.

ATA-MIR5 es una capa sutil de limo arcilloso pardo grisáceo, poco orgánico, con estructura po- liédrica, fragmentos milimétricos de ceniza y carbones. El límite con MIR6 es gradual. Nivela las irregularidades de MIR6, contiene escaso material y egagrópilas bien conservadas.

ATA-MIR6 presenta una sucesión de facies análoga a MIR4, con elevada variabilidad, presencia de materiales quemados y organización en niveles más o menos irregulares o en manchas (para las facies se usan las mismas letras de MIR4).

Los conjuntos MIR6 y MIR4 se componen, casi exclusivamente, de aportaciones antrópicas. Entre las facies nombradas se encuentran acumulaciones de productos de combustión de restos vegetales (carbones, ceniza mezclada con fosfatos, limo, etc.) y deyecciones animales (excrementos y urea, ésta última por confirmar analíticamente). Unas derivan de la combustión de material in situ, como indican las fibras vegetales conservadas (facies $6 \mathrm{f} / 4 \mathrm{f}$ ) y el 
sedimento rubefactado (facies $6 r / 4 r$ ). Los procesos sin- y postdeposicionales son importantes, sobre todo los debidos a la actividad animal, pero no tanto para impedir la correcta identificación estratigráfica y excavación de los conjuntos. Su aspecto es el típico de los sedimentos de redil, conocidos en la bibliografía en lengua inglesa como animal dung acumulation, burnt layers, ofumier o stallatico, en la francesa e italiana respectivamente. Estos sedimentos se originan durante el uso de cuevas o abrigos por parte de comunidades de pastores (de ovejas y cabras, según se ha observado en la mayoría de los casos conocidos), como producto de la acumulación de excrementos y de paja en superficie, ya sea para formar el lecho de los animales o para su alimentación (2); en algunos casos se documenta la periódica combustión de estos residuos. Pese a no disponer aún de los resultados del trabajo de laboratorio, el levantamiento detallado de campo permite realizar esta atribución preliminar.

La acumulación antrópica se detuvo durante el lapso de tiempo representado por MIR5, conjunto dominado por procesos naturales, deposición de sedimento de vertiente y sucesiva edafogénesis como horizonte $\mathrm{A}$, con incorporación de materia orgánica y débil estructuración. La existencia en este conjunto de egagrópilas enteras, en perfecto estado de conservación, indica una escasa o nula presencia antrópica en la cueva durante la deposición de estos sedimentos, ya que, en contextos de ocupación humana, dichos elementos son rápidamente disgregados por pisoteo.

El conjunto MIR3 procede de acumulación tanto natural (fracción fina de la vertiente y piedras calizas del techo) como antrópica (carbones y ceniza), con homogeneización de la matriz sedimentaria debida probablemente a la actividad biológica sindeposicional.

Cabe destacar que estos sedimentos representan productos de acumulación casi exclusivamente

(2) Dichos sedimentos han sido descritos en yacimientos y unidades comprendidas entre el Neolítico antiguo y la Edad del Hierro, en la margen mediterránea: Arene Candide (Maggi, 1997; Macphail et al., 1997), Fiavè-Carera (Karg, 1998), Riparo Gaban (Angelucci y Boschian, e.p.) y varias cuevas del Carso de Trieste (Boschian y Montagnari-Kokelj, 2000), en Italia; Fontjuvenal (Brochier, 1988), Grotte Antonnaire (Argant et al., 1991) y Caune de Bélesta (Brochier et al., 1998) entre otros yacimientos franceses (vease también Brochier, 1983; Brochier, 1996; Courty et al., 1992); Cova del Parco, Cova de la Guineu (Bergadà, 1997) y Can Sadurní (Blasco et al., 1999), en Cataluña; Santa Maira, Bolumini y Cova de les Cendres (Badal, 1999) en el Levante peninsular; Balma de la Margineda en Andorra (Brochier y Claustre, 1994; Brochier, 1995); Egolzwil 3 (Rasmussen, 1989; Rasmussen, 1993), Arbon Bleiche 3 (Akeret et al., 1999) en Suiza. antrópica y que su contenido de información arqueológica, pese la escasez de artefactos u otras clases de materiales arqueológicos, es generalmente muy alto. El caso de El Mirador constituye la primera señalización de sedimentos de redil quemados periódicamente en la Meseta y, considerando la distribución a nivel europeo, en contexto geográfico continental.

\section{DATACIONES}

Hasta el momento disponemos de dataciones radiométricas realizadas sobre elementos procedentes de los conjuntos MIR4 y MIR6. Del conjunto MIR4 se han datado dos muestras de carbón vegetal y un hueso. Los carbones han sido recuperados en los sedimentos de redil, uno de ellos, de Quercus sp. perennifolio, a techo del conjunto (Beta-154894) y el otro, de Quercus sp. caducifolio, en la base (Beta-153366). El hueso (Beta153365), un fragmento de tibia humana, procede de la acumulación de restos humanos documentada en el interior de una pequeña fosa excavada en el conjunto MIR4.

La muestra de MIR6 (Beta-153367) es también un carbón, de Quercus sp. perennifolio, recuperado en un nivel de corral.

Las muestras han sido analizadas siguiendo el método del radiocarbono con $A M S$ por el laboratorio Beta Analytic Inc. de la University Branch de Miami (Florida, USA). Los resultados obtenidos se indican en la tabla 1.

\section{RESTOS VEGETALES}

La información de que disponemos actualmente sobre los restos vegetales recuperados en El Mirador proviene del análisis antracológico. Los estudios polínicos, de fitolitos y carpológicos se encuentran actualmente en curso. Sobre estos últimos, sólo cabe señalar que la mayor parte de semillas recuperadas en los conjuntos MIR3 y MIR4 corresponden a cereales.

Durante la realización del sondeo se ha cribado por flotación con agua la totalidad del sedimento extraído, con el objetivo de recuperar el máximo de material. Las mallas utilizadas han sido de $4 \mathrm{~mm}$, $1 \mathrm{~mm}$ y $0.5 \mathrm{~mm}$ y el análisis antracológico se ha realizado sobre los restos carbonizados procedentes de la malla de $4 \mathrm{~mm}$. Hasta el momento se ha 


\begin{tabular}{|c|c|c|c|c|c|c|c|c|}
\hline 1 & 2 & 3 & 4 & 5 & 6 & 7 & 8 & 9 \\
\hline ATA-MIR4 & carbón & IV & Beta-154894 & $\mathbf{3 0 2 0} \pm \mathbf{4 0}$ & $\mathbf{3 0 4 0} \pm \mathbf{4 0}$ & $3350-3140$ & $1400-1190$ & $-23.9 \%$ o \\
\hline ATA-MIR4 & hueso & I & Beta-153365 & $\mathbf{3 5 8 0} \pm \mathbf{4 0}$ & $\mathbf{3 6 7 0 \pm 4 0}$ & $4100-3880$ & $2140-1940$ & $-19.3 \%$ o \\
\hline ATA-MIR4 & carbón & IV & Beta-153366 & $\mathbf{3 3 8 0} \pm \mathbf{4 0}$ & $\mathbf{3 4 0 0 \pm 4 0}$ & $3720-3560$ & $1760-1610$ & $-23.8 \%$ o \\
\hline ATA-MIR6 & carbón & IV & Beta-153367 & $\mathbf{4 7 6 0 \pm 4 0}$ & $\mathbf{4 7 8 0 \pm 4 0}$ & $5600-5460$ & $3650-3510$ & $-23.5 \%$ \\
\hline
\end{tabular}

Tab. 1. Sierra de Atapuerca, cueva de El Mirador. Resultados de las dataciones radiométricas.

Leyenda: 1, conjunto arqueológico; 2 , material datado; 3 , relación de seguridad entre la muestra y el objeto datado (Waterbolk, 1971); 4, referencia del laboratorio; 5 y 6, edad radiocarbónica medida (5) y edad radiocarbónica convencional (6), en años $14 \mathrm{C}$ bp; 7 y 8 , intervalo $2 \sigma$ de la datación calibrada, en años cal BP (7) y en años cal BC (8); 9, 13C/12C ratio.

realizado el estudio de 573 fragmentos; 92 procedentes de MIR3 y 481 de las tres tallas superiores del conjunto MIR4 (cotas -1200/-1210, -1210/1220 y $-1220 /-1240$. Las cotas se expresan en centímetros y señalan la profundidad respecto al punto cero teórico de la excavación). El número de fragmentos es todavía reducido para considerar las frecuencias relativas de cada una de las tallas. Según algunos autores, el número mínimo de carbones que se deben estudiar para que la muestra sea representativa es de 250 fragmentos (Heinz 1990; Badal 1992). Para la identificación se han utilizado las técnicas habituales en antracología (Chabal et al. 1999), apoyada en los atlas de anatomía de la madera de Schweingruber (1990) y Jacquiot y otros (1973).

El análisis antracológico nos ha permitido identificar 14 taxones: Pinus tipo sylvestris/nigra (pino albar/ pino negral), Quercus sp. caducifolio (robles), Quercus sp. perennifolio (encina/alcornoque/ coscojo), Quercus sp., cf. Betula (cf. abedul), Fraxinus sp. (fresno), Corylus avellana (avellano), Cornus sanguinea (cornejo), Hedera sp. (hiedra), Sambucus sp. (saúco), Leguminosae (leguminosas), Salix sp. (sauce), Prunus sp. (rosaceas), Rosaceae/Pomoideae (pomoideas) (Tab. 2).

\begin{tabular}{|c|c|c|c|c|c|c|c|c|}
\hline \multirow[b]{3}{*}{ Taxón } & \multirow{2}{*}{\multicolumn{2}{|c|}{ MIR3 }} & \multicolumn{6}{|c|}{ MIR4 } \\
\hline & & & \multicolumn{2}{|c|}{$-1200 /-1210$} & \multicolumn{2}{|c|}{$-1210 /-1220$} & \multicolumn{2}{|c|}{$-1220 /-1240$} \\
\hline & $\mathbf{N}^{\circ}$ frags. & $\%$ & $N^{\circ}$ frags & $\%$ & $N^{\circ}$ frags. & $\%$ & $\mathrm{~N}^{\circ}$ frags. & $\%$ \\
\hline Pinus tipo sylvestris/nigra & 0 & 0.0 & 1 & 0.5 & 2 & 1.4 & 5 & 3.6 \\
\hline Cornus sanguinea & 0 & 0.0 & 1 & 0.5 & 0 & 0.0 & 0 & 0.0 \\
\hline Corylus avellana & 2 & 2.2 & 3 & 1.5 & 1 & 0.7 & 3 & 2.2 \\
\hline Fraxinus sp. & 1 & 1.1 & 0 & 0.0 & 3 & 2.1 & 10 & 7.2 \\
\hline Hedera sp. & 0 & 0.0 & 0 & 0.0 & 1 & 0.7 & 0 & 0.0 \\
\hline Leguminosae & 0 & 0.0 & 0 & 0.0 & 0 & 0.0 & 2 & 1.4 \\
\hline Prunus sp. & 1 & 1.1 & 0 & 0.0 & 0 & 0.0 & 2 & 1.4 \\
\hline Quercus sp. perennifolio & 33 & 35.9 & 42 & 21.3 & 22 & 15.2 & 36 & 25.9 \\
\hline Quercus sp. & 1 & 1.1 & 1 & 0.5 & 1 & 0.7 & 2 & 1.4 \\
\hline Quercus sp. caducifolio & 46 & 50.0 & 131 & 66.5 & 96 & 66.2 & 60 & 43.2 \\
\hline Rosaceae/Pomoideae & 0 & 0.0 & 5 & 2.5 & 7 & 4.8 & 7 & 5.0 \\
\hline Salix sp. & 0 & 0.0 & 3 & 1.5 & 0 & 0.0 & 0 & 0.0 \\
\hline Sambucus sp. & 2 & 2.2 & 3 & 1.5 & 4 & 2.8 & 0 & 0.0 \\
\hline cf. Betula & 0 & 0.0 & 1 & 0.5 & 0 & 0.0 & 0 & 0.0 \\
\hline cf. Hedera sp. & 1 & 1.1 & 0 & 0.0 & 0 & 0.0 & 0 & 0.0 \\
\hline cf. Prunus & 1 & 1.1 & 0 & 0.0 & 1 & 0.7 & 0 & 0.0 \\
\hline cf. Rosaceae/Pomoideae & 0 & 0.0 & 0 & 0.0 & 1 & 0.7 & 2 & 1.4 \\
\hline cf. Sambucus sp. & 0 & 0.0 & 2 & 1.0 & 1 & 0.7 & 0 & 0.0 \\
\hline Conífera indeterminada & 0 & 0.0 & 0 & 0.0 & 0 & 0.0 & 3 & 2.2 \\
\hline Indeterminable & 1 & 1.1 & 2 & 1.0 & 3 & 2.1 & 3 & 2.2 \\
\hline Indeterminado & 3 & 3.3 & 2 & 1.0 & 2 & 1.4 & 4 & 2.9 \\
\hline Total & 92 & 100 & 197 & 100 & 145 & 100 & 139 & 100 \\
\hline
\end{tabular}

Tab. 2. Resultados del análisis antracológico de la cueva de El Mirador.

T. P., 59, n. ${ }^{\circ} 1,2002$ 
Por lo que respecta a los datos paleoecológicos que aporta este estudio, de forma preliminar, cabe resaltar la importancia de Quercus sp. caducifolio en toda la sucesión estratigráfica estudiada. La asociación de este grupo con otras especies de carácter mesófilo como el cornejo, el fresno, el avellano y las rosáceas nos indica la existencia de una formación de carácter mixto. Asimismo, encontramos algunos elementos perennifolios, como Quercus sp. perennifolio y leguminosas con una presencia significativa. En relación con la determinación de Quercus sp. perennifolio, si tenemos en cuenta el límite de la distribución actual de Quercus coccife$r a$ (coscoja), situado en el río Duero (Blanco et al., 1998), podríamos pensar que en la sierra crecería la encina, que es la especie que presenta una mayor extensión en la actualidad. De todos modos, debemos considerar que existe una limitación debida a la falta de criterios anatómicos para su distinción. Además, cabe destacar la presencia de taxones que crecen en ambientes de ribera como el sauce y el saúco, que en la actualidad se hallan en la ribera del río Arlanzón. Los resultados muestran una continuidad en la sucesión en cuanto a la presencia de los taxones identificados. El estudio de un mayor número de carbones en próximos trabajos nos permitirá reconocer las tendencias evolutivas de la dinámica vegetal.

En el contexto de un lugar de estabulación de ganado como el documentado en el conjunto MIR4, la presencia de determinadas especies puede estar relacionada con la alimentación del rebaño. En este sentido, la explotación preferente de Quercus, tanto caducifolios como perennifolios, si bien puede estar determinada por el tipo de formación vegetal, también puede ser debida al uso de estas especies como forraje en los momentos en que el rebaño se hallaba estabulado. Según datos etnográficos y arqueológicos la alimentación del ganado durante el invierno se basaba en el consumo de forraje arbóreo (Rasmussen, 1993; Halstead y Tierney, 1998; Haas et al., 1998; Badal, 1999; Akeret et al., 1999). Los períodos de lluvias y nieve, así como la escasez de ramón y la falta de pastos durante estas épocas del año obligaban a realizar una previsión, podando las ramas jóvenes que se guardaban para ser utilizadas en invierno (Halstead y Tierney, 1998). Entre las mas apreciadas se hallan las hojas y ramas tiernas de robles, fresnos y acebuches (Bolaños, 1960; Blanco et al., 1998; Badal, 1999). Una vez consumidas por el rebaño, los restos de las ramas podían ser también utilizados como combustible. No obs- tante, no puede descartarse el aporte a la cavidad de las especies documentadas en condición de leña, dado que se trata de buenos combustibles, y la explotación de algunas de ellas, como el roble, la encina, el avellano y las rosáceas, por sus frutos. Un análisis más profundo del depósito, así como de los restos de excrementos, semillas, pólenes, etc., nos permitirá en un futuro profundizar en el conocimiento de la utilización de los recursos vegetales.

\section{RESTOS FAUNÍSTICOS}

Se han recuperado 1047 restos óseos de animales, de los que el 3,5\% corresponden a MIR1 o superficial, el $18 \%$ a MIR2, formado por los sedimentos de relleno de las madrigueras, $25,1 \%$ a MIR3 y el 53,4\% a MIR4. Todas las especies documentadas en los dos conjuntos superiores se encuentran también identificadas en los dos inferiores, por lo que sólo sobre los conjuntos MIR3 y MIR4 caben hacer valoraciones biológicas y culturales. Además, buena parte del contingente recuperado en MIR2 corresponde a lagomorfos muy completos, con individuos infantiles, que denotan el carácter intrusivo de los conejos. La diferencial mineralización de los restos en los conjuntos MIR1 y MIR2 sugiere cierta acontemporaneidad de los elementos y de sus correspondientes entidades biológicas.

La fragmentación de los vestigios es abundante, pero no intensa, por lo que se han podido adscribir a especies concretas la mitad de los restos recuperados (Tab. 3). Cuando la determinación específica no era posible, hemos optado por una adscripción a categorías de peso. Los elementos de especies de talla media (animales de 50 a $100 \mathrm{~kg}$ ) predominan con claridad sobre los individuos de talla grande y pequeña.

La asociación identificada es de marcado carácter doméstico, destacando la contribución de los ovicápridos, con un ligero predominio de la oveja frente a la cabra; grandes bóvidos y cerdos forman el segundo grupo de las especies domésticas, con pocos restos de caballo y de perro. Se trata por tanto de un espectro ganadero característico de los yacimientos de esta época (Altuna, 1986). La única diferencia encontrada entre los conjuntos MIR4 y MIR3 se refiere a una ligera reducción en el nivel más reciente de la cabaña vacuna y caballar.

Los restos de conejos son muy numerosos en ambos conjuntos, en particular en MIR3 donde igualan a los de ovicápridos. Numerosos fragmen- 


\begin{tabular}{|c|c|c|c|c|c|c|c|c|c|c|c|c|}
\hline & \multicolumn{3}{|c|}{ MIR1 } & \multicolumn{3}{|c|}{ MIR2 } & \multicolumn{3}{|c|}{ MIR3 } & \multicolumn{3}{|c|}{ MIR4 } \\
\hline & NR & $\%$ & NMI & NR & $\%$ & NMI & NR & $\%$ & NMI & NR & $\%$ & NMI \\
\hline Aves & 1 & 2,7 & 1 & 5 & 2,5 & 2 & - & - & - & 4 & 0,7 & 1 \\
\hline Bos taurus & 1 & 2,7 & 1 & 4 & 2,1 & 1 & 9 & 3,4 & 2 & 39 & 6,9 & 2 \\
\hline Canis familiaris & 2 & 5,4 & 1 & - & - & - & 1 & 0,4 & 1 & - & - & - \\
\hline Canidae & 1 & 2,7 & 2 & - & - & - & 1 & 0,4 & 1 & 6 & 1,1 & 3 \\
\hline Carnivorae & 2 & 5,4 & - & - & - & - & - & - & - & - & - & - \\
\hline Cervus elaphus & - & - & - & 1 & 0,5 & 1 & 1 & 0,4 & 1 & 4 & 0,7 & 1 \\
\hline Cervidae & 1 & 2,7 & 1 & 1 & 0,5 & - & 3 & 1,1 & - & 6 & 1,1 & 1 \\
\hline Equus caballus & - & - & - & 2 & 1 & 2 & 2 & 0,8 & 1 & 18 & 3,2 & 3 \\
\hline Ovis aries & 1 & 2,7 & 1 & 3 & 1,6 & 2 & 3 & 1,1 & 2 & 7 & 1,2 & 2 \\
\hline Capra hircus & - & - & - & - & - & - & 2 & 0,8 & 1 & 2 & 0,4 & 1 \\
\hline Ovicapridae & 2 & 5,4 & - & 25 & 13,3 & - & 36 & 13,7 & - & 77 & 13,7 & - \\
\hline Oryctolagus & - & - & - & 28 & 14,9 & 3 & 23 & 8,7 & 3 & 22 & 3,9 & 4 \\
\hline Suidae indet & - & - & - & 5 & 2,5 & - & - & - & - & 2 & 0,4 & - \\
\hline Sus scrofa & 1 & 2,7 & 1 & - & - & - & 1 & 0,4 & 1 & 6 & 1,1 & 1 \\
\hline Sus domesticus & 2 & 5,4 & 1 & 6 & 3,2 & 2 & 9 & 3,4 & 2 & 15 & 2,7 & 3 \\
\hline Talla pequeña & 4 & 10,8 & - & 14 & 7,5 & - & 18 & 6,8 & - & 10 & 1,8 & - \\
\hline Talla media & 7 & 18,9 & - & 47 & 25 & - & 55 & 21 & - & 163 & 29 & - \\
\hline Talla grande & 10 & 27 & - & 25 & 13,3 & - & 24 & 9,1 & - & 70 & 12,4 & - \\
\hline Indeterminados & 2 & 5,4 & - & 22 & 11,7 & - & 75 & 28,5 & - & 108 & 19,2 & - \\
\hline Total & 37 & & 9 & 188 & & 13 & 263 & & 15 & 559 & & 22 \\
\hline
\end{tabular}

Tab. 3. Resultados del análisis taxonómico de los restos faunísticos de los conjuntos MIR1, MIR2, MIR3 y MIR4.

tos de los lagomorfos están quemados y con similar mineralización a los de los restantes taxones, pero dado que no siempre es así será importante realizar un estudio biométrico y tafonómico comparativo. En cualquier caso, la importancia del conejo en la dieta, a tenor de su biomasa, sería siempre inferior a la de la cabaña doméstica.

La fauna silvestre se completa con el ciervo y el jabalí, animales del entorno de la sierra que unidos no llegan al 5\% de los restos, por lo que las especies cinegéticas constituyen un recurso marginal en la alimentación de estos habitantes.

El estudio de los espectros de edad revela que la cabaña era sacrificada a edades variables, de lo que deducimos una dualidad de aprovechamiento: consumo de carne de calidad (jóvenes), y aprovechamiento de productos secundarios (adultos), asegurándose también el reemplazo de dicha cabaña. Esta doble estrategia parece propia de sociedades complejas que controlan los rebaños. La presencia de un feto de suido y la abundancia de animales domésticos inmaduros (casi la mitad de los individuos) nos hace plantear, como hipótesis, la estabulación y cría en el lugar del ganado.

Son numerosas las huellas de marcas de corte y fracturación, lo que evidencia que buena parte del conjunto óseo procede de la actividad culinaria. Dichas señales se aprecian en todos los taxones sin distinción, y pueden adscribirse a actividades tan diversas como al desollado, despiece y descarnación. La abundancia de huesos quemados documentada puede referirse tanto a la actividad culinaria como a la combustión de las heces. Por último, otras alteraciones visualizadas sobre las superficies óseas corresponden a señales de mordeduras de cánidos. La identificación de cánidos domésticos en El Mirador sugiere su autoría en tales señales.

\section{RESTOS HUMANOS}

La presencia de restos óseos humanos ha sido documentada tanto en el conjunto MIR3 como en MIR4. Parte de estos huesos se encontraban dispersos en las diferentes superficies de ocupación y, aparentemente, fuera de su contexto original. Únicamente, durante la excavación del conjunto MIR4, se documentó una acumulación intencional, formada por unos 200 restos humanos, tanto óseos como dentales, que habían sido depositados en el interior de una pequeña fosa de $40 \mathrm{~cm}$ de longitud por $25 \mathrm{~cm}$ de anchura, de planta ovalada, y una profundidad 
mínima de $20 \mathrm{~cm}$. Como ya se ha comentado anteriormente, el entorno de dicha acumulación, especialmente su parte superior, había sido afectado por madrigueras de conejos. Esta bioturbación rompía la continuidad de la fosa y hacía imposible reconocer la superficie desde donde se inició su excavación: en la última fase de formación del conjunto MIR4 o durante las ocupaciones de MIR3.

Los restos humanos pertenecen, según los estudios preliminares, a un mínimo de seis individuos, de ambos sexos y de diversas edades. En la acumulación no están presentes los esqueletos completos ni se hallan representadas todas las partes esqueléticas; tampoco se documentó ningún elemento en conexión anatómica. Proporcionalmente se documenta una mayor representación de huesos largos de las extremidades y partes del cráneo, respecto a huesos de menores dimensiones; los elementos correspondientes a manos y pies estan prácticamente ausentes. La mayor parte de los restos, entre los que cabe destacar seis neurocráneos que muestran evidencias de haber sido separados intencionalmente, presentan fracturas y marcas de corte de origen antrópico. La disposición de los diferentes elementos parece indicar que primeramente se depositaron los neurocráneos en la base de la fosa y a continuación se colocaron el resto de huesos por encima de estos.

En la base de la acumulación de restos humanos se halló parte de un recipiente de cerámica de tendencia vertical, con paredes y borde ligeramente entrantes en su parte superior de $13 \mathrm{~cm}$ de diámetro, pasta de color negro, y superficie ligeramente escobillada sin motivos decorativos (Fig. 4: 9).

La presencia de marcas de corte relacionadas con el descarnado de los huesos, la fracturación intencional de los mismos y la separación sistemática del neurocráneo nos indicaría el desarrollo de algún tipo de ritual funerario previo al enterramiento.

Los paralelos de que disponemos en la Península Ibérica sobre la práctica de separar la bóveda craneana del resto del cráneo, lo que da lugar a los denominados en la bibliografía como "cráneos copa", son escasos y de diferentes periodos cronológicos. La primera referencia de que se tiene noticia procede de las excavaciones realizadas por $\mathrm{H}$. Obermaier entre 1911 y 1913 en la cueva de El Castillo (Santander), en las que se recuperaron dos "cráneos copa" atribuidos al Magdaleniense (Obermaier, 1925). Mas tarde, se localizaron dos nuevos "cráneos copa" en la provincia de Guipúzcoa; uno en los años 30, en las Cuevas de Urtiaga (Barandia-

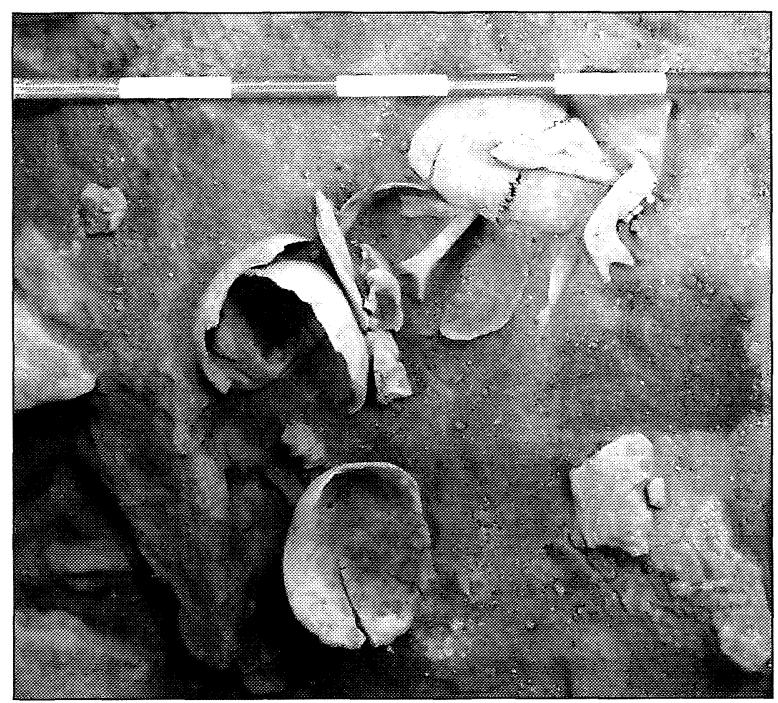

Lám. I. Detalle de la base de la acumulación intencional de restos humanos depositada en una pequeña fosa excavada en el conjunto MIR4. Se observan cinco de los seis neurocráneos localizados en la inhumación.

rán, 1952), y otro en los años 40, atribuido al Bronce Antiguo, en la cueva de Txispiri (Armendáriz y Etxeberría, 1983), si bien sobre este último existen dudas sobre su adscripción al grupo de "cráneos copa" (Etxeberría, 1990). Al cráneo de Txispiri se halló asociado un gran vaso de tendencia cilíndrica y fondo plano, con dos cordones digitados paralelos al borde, y la superficie recubierta por una capa del denominado "barro plástico". El último ejemplar de "cráneo copa" conocido en la Península Ibérica, se localizó a finales de los años 70 en la cueva de la Carihuela de Piñar (Granada), y se interpreta como perteneciente al Bronce I Inicial. En este caso, el estudio antropológico indica que se trata de un individuo adulto, probablemente masculino. Al igual que en la cueva de Txispiri, el cráneo de la Carihuela se hallaba asociado a un recipiente, en este caso de cuerpo globular y borde ligeramente exvasado (García y Carrasco, 1981).

En el caso de El Mirador la inhumación debe situarse cronológicamente en el Bronce Medio o en el Bronce Tardío, dado que la excavación de la fosa donde se depositaron los restos humanos es posterior a la formación del nivel de corral de la base del conjunto MIR4, de donde se extrajo el carbón que ha sido datado en $3400 \pm 40 \mathrm{BP}$. No obstante, la datación de uno de los huesos de la acumulación indica que la muerte del individuo al que pertenecía se produjo en el Bronce Antiguo. La hipótesis 
que se plantea para explicar el desfase entre ambas fechas, si aceptamos que las muestras datadas no están contaminadas, es que se trate de una inhumación de tipo secundario realizada durante el Bronce Medio o un momento posterior, con restos procedentes de una inhumación del Bronce Antiguo.

\section{INDUSTRIA LÍTICA}

Durante la excavación de los conjuntos MIR3 y MIR4 se han recuperado un total de 261 restos líticos. Su distribución por conjuntos estratigráficos y categorías estructurales aparece representada en la tabla 4. En general, el número de restos líticos es reducido en ambas unidades estratigráficas. El conjunto MIR4 es el que cuenta con un mayor número de efectivos, aunque en este caso hay que tener en cuenta que se trata de la unidad estratigráfica de mayor potencia. La clasificación por categorías estructurales y el análisis de los restos se ha realizado en el marco del Sistema Lógico-Analítico (Carbonell et al., 1983, 1992).

Hasta el momento no se han documentado acumulaciones bien delimitadas de restos líticos, lo cual, añadido al escaso número de artefactos, no permite plantear la existencia de áreas de talla en el sector excavado. Por otra parte, la distribución volumétrica de las lascas muestra una subrepresentación de restos de pequeño tamaño.

\begin{tabular}{|l|c|c|c|}
\cline { 2 - 4 } \multicolumn{1}{c|}{} & $3 \mathrm{~A}$ & 4 & TOTAL \\
\hline BP & 15 & 53 & 68 \\
\hline FBP & 7 & 91 & 98 \\
\hline BPF & 2 & 9 & 11 \\
\hline BN2G & 2 & 15 & 17 \\
\hline BN1G & -- & 4 & 4 \\
\hline Frag. & 3 & 23 & 26 \\
\hline Bn & 2 & 35 & 230 \\
\hline TOTAL & 31 & 230 & 261 \\
\hline
\end{tabular}

Tab. 4. Distribución de los restos líticos por conjuntos estratigráficos y categorías estructurales.

Las Bases Positivas (BP) y los Fragmentos de Base Positiva (FBP) son las categorías más representadas en los dos conjuntos estudiados. Los artefactos retocados y, especialmente, los núcleos son poco frecuentes. Destaca el alto porcentaje de Bases naturales en el conjunto MIR4 (15,2\%), algunas de ellas con evidencias de haber sido utilizadas como percutores y/o machacadores.

\begin{tabular}{|l|c|c|c|}
\cline { 2 - 4 } \multicolumn{1}{c|}{} & MIR3 & MIR4 & TOTAL \\
\hline Arenisca & 1 & 17 & 18 \\
\hline Caliza & 11 & 17 & 28 \\
\hline Cristal de Roca & -- & 6 & 6 \\
\hline Cuarcita & 1 & 23 & 24 \\
\hline Cuarzo & -- & 1 & 1 \\
\hline Gneis & -- & 1 & 1 \\
\hline Sílex & 18 & 165 & 183 \\
\hline TOTAL & 31 & 230 & 261 \\
\hline
\end{tabular}

Tab. 5. Distribución de los restos líticos por conjuntos estratigráficosy materias primas.

La distribución por materias primas (Tab. 5) muestra el predominio del sílex en ambos conjuntos. El porcentaje del sílex se incrementa si tenemos en cuenta solamente los restos derivados de procesos de talla, lo que refuerza su carácter preferencial en las actividades técnicas. Otros materiales bien representados son la cuarcita y la arenisca, sobre todo en el conjunto MIR4, aunque aparecen básicamente en forma de Bases naturales (por ejemplo, de los 23 artefactos de cuarcita documentados en dicho conjunto, 22 corresponden a Bn). Los restos de caliza tienen dos orígenes diferentes. En primer lugar, hay una serie de elementos que corresponden a procesos de talla realizados a partir de la caliza procedente de las propias formaciones en las que se abre la cueva. Estos restos muestran unas secuencias operativas poco desarrolladas y probablemente corresponden a procesos de talla de carácter expeditivo y oportunista, con frecuencia de lascas de tamaño grande que presentan talones y caras dorsales total o mayoritariamente corticales. En segundo lugar, hay un aporte de cantos de caliza procedentes de las formaciones fluviales del entorno; estos materiales aparecen básicamente en forma de bases naturales $(\mathrm{Bn})$, especialmente en el conjunto MIR4.

El escaso número de restos documentado en ambos conjuntos dificulta la reconstrucción de las secuencias de explotación y de los criterios técnicos que definen los métodos de talla utilizados. En este sentido hay que recordar nuevamente el reducido número de núcleos existente en la muestra analizada. Los que se han recuperado exhiben un grado de reducción muy limitado y no presentan estrategias bien definidas. Se trata de artefactos de considerables dimensiones en los que apenas se ha iniciado una explotación bifacial o unifacial desde el plano horizontal. En líneas ge- 


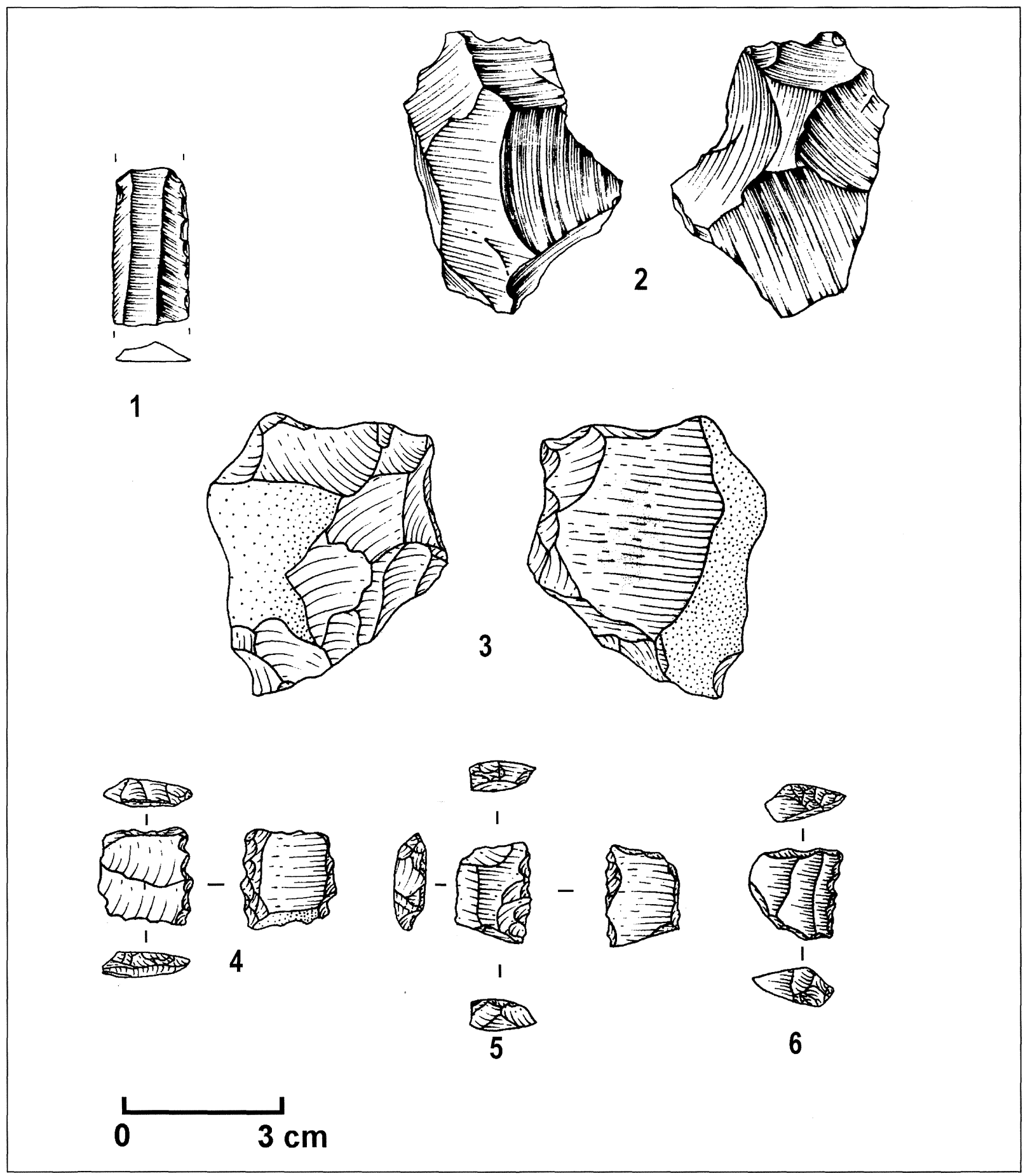

Fig. 3. Artefactos retocados del conjunto MIR-4: 1. Fragmento de lámina con retoques marginales. 2-3. Denticulados. 46. Elementos de hoz.

nerales, se aprecia un predominio claro de las BP no laminares.

El análisis de las Bases Positivas muestra la existencia de diferencias tipométricas entre MIR3 y MIR4. El tamaño de las BP tiende a ser considerablemente mayor en el conjunto MIR4 que en MIR3, y sólo MIR4 muestra una representación de lascas de tamaño grande. Llama la aten- 
ción en este conjunto la ausencia de los módulos volumétricos intermedios y la representación preferencial de elementos correspondientes a estadios avanzados de la cadena operativa, lo que sugiere una clara distorsión de lo que sería la distribución normal en el caso de que el registro lítico fuera el resultado del desarrollo in situ de cadenas operativas completas.

Los artefactos retocados muestran un predomino claro del retoque simple, aunque la modalidad abrupta también se encuentra bien representada. Las extracciones son profundas en la mayoría de los casos. En cuanto a la dirección, predomina la combinación directo-indirecto, que en general corresponde a las piezas que asocian retoques planos y simples. En estos casos, las extracciones simples aparecen sobre la cara dorsal, mientras que las planas aparecen sobre la cara ventral, documentándose generalmente fenómenos de sobreimposición. Desde el punto de vista tipológico, son frecuentes las lascas retocadas de difícil adscripción. Entre los artefactos que han podido ser clasificados en algún grupo tipológico, la mayoría corresponde al denominado grupo del sustrato, destacando especialmente la alta presencia de denticulados (Fig. 3: 2 y $3)$. Entre estos últimos destaca la tendencia a producir morfologías convergentes. Los artefactos tipológicamente más característicos son los denominados elementos de hoz, de los que se han documentado tres ejemplares en el conjunto MIR4 (Fig. 3: 4-6). Estos elementos muestran una clara estandarización, tanto a nivel tipométrico como morfotécnico. Se trata de objetos de forma cuadrada o rectangular que presentan un dorso abrupto en dos o tres de sus laterales, mientras que en un lateral muestran un filo denticulado con extracciones simples. Elementos de este tipo ha sido descritos en numerosos yacimientos de la Edad del Bronce en la Submeseta norte (p. ej. Palomino y Rodríguez Marcos, 1994; Pérez Rodríguez et al., 1994; Rodríguez Marcos y Abarquero, 1994; Rodríguez Marcos y Palomino, 1997). Del resto de artefactos retocados sólo cabe destacar la aparición de un buril sobre truncadura en el conjunto MIR4.

\section{INDUSTRIA ÓSEA}

En el conjunto MIR4 sólo se han recuperado dos instrumentos sobre hueso: un punzón sin base y una esquirla apuntada. Para su descripción se ha tomado como referencia el trabajo de Rodanés (1987) so- bre la industria ósea del Valle del Ebro. Ambos objetos han sido elaborados sobre fragmentos de diáfisis de hueso largo pertenecientes a animales de talla media. El punzón, de sección cóncavo-convexa, tiene unas dimensiones de $65 \times 14$ x $4 \mathrm{~mm}$, presenta el extremo distal redondeado, y una fractura en la parte proximal que nos impide conocer como era su base. La esquirla apuntada tiene unas dimensiones de $56 \times 14$ × 2 mm y tan solo presenta la cara exterior pulimentada. Fracturas en sus extremos distal y proximal impiden reconocer su morfología original.

\section{ELEMENTOS CERÁMICOS}

No son muchos los materiales cerámicos recuperados durante las dos primeras campañas de excavación en la cueva de El Mirador si nos atenemos al volumen de sedimento sobre el que se ha intervenido. Concretamente el elenco cerámico exhumado asciende a un total de 594 fragmentos: 29 en MIR1, 145 en MIR2, 174 en MIR3 y 246 en MIR4.

El registro recuperado en MIR1 y MIR2 puede calificarse como material de revuelto por la presencia de cerámicas realizadas a torno de época Contemporánea. Por su parte, el material cerámico de MIR3 y MIR4 conforma una colección bastante homogénea, lo que nos permite abordar su presentación de forma conjunta. La mayor parte de las cerámicas muestran algún tipo de tratamiento en sus superficies, siendo los mas comunes el alisado $(50 \%)$ y el bruñido (14\%). En cuanto a sus pastas, generalmente han sido bien decantadas y muestran una cocción en ambiente reductor. Los desgrasantes empleados presentan una cierta variabilidad: predomina el uso de la calcita y el cuarzo, y en menor medida mica, cerámica machacada y elementos vegetales. Esta variabilidad también afecta al tamaño de las partículas empleadas, predominando las que no superan el milímetro de grosor, aunque en las cerámicas más toscas se produce un aumento de dicho tamaño que llega a alcanzar los cuatro milímetros.

\section{Formas}

El elevado grado de fragmentación de los materiales - la mayor parte no superan $l o s 5 \mathrm{~cm}$ en ninguna de sus dimensiones- dificulta en gran medi-

T. P., 59, n. ${ }^{\circ} 1,2002$ 
da la identificación de las formas presentes en el yacimiento, aunque podemos apuntar que predominan las simples sobre las compuestas. Entre las primeras destaca la presencia de cuencos en sus distintas variedades, las ollas globulares y los vasos con gran desarrollo en altura, mientras que entre las segundas diferenciamos exclusivamente tazas carenadas y perfiles en "S" (Figs. 4: 1-9 y 5:1-2). Estos últimos, salvo un ejemplar, se muestran siempre bajo una tendencia entrante. En cuanto a los fondos únicamente hemos recuperado 10 ejemplares, todos ellos planos, de los que 4 aparecen reforzados por una moldura (Fig. 5: 8).

El repertorio cerámico se completa con una de las llamadas "fichas recortadas", que en nuestro caso se presenta con forma ovalada (Figura 5: 4), y a un fragmento de cuchara figulina a la que le falta el mango y parte del borde (Fig. 5: 6), ambos recuperados en el conjunto MIR3.

\section{Decoraciones}

El muestrario cerámico es predominantemente liso $(94,3 \%)$, con presencia minoritaria de decoración impresa, incisa, excisa y plástica. La decoración impresa es la mas utilizada, siendo los labios el lugar preferido para su aplicación. En cuanto a los elementos utilizados para llevar a cabo esta técnica, predomina el empleo de algún tipo de instrumento y en menor medida la impresión con dedos y uñas. En este apartado debemos incluir también un par de ejemplares que muestran en toda su superficie una decoración un tanto particular, consistente en la realización de suaves pellizcos sobre el barro (Fig. 4: 6). Las incisiones sirven para confeccionar motivos muy simples - primordialmente líneas horizontales-, y cuando el tamaño del fragmento permite apreciarlo aparecen combinadas con otro tipo de técnicas. Sólo excepcionalmente muestran un motivo de líneas paralelas verticales que decoran toda la superficie del vaso (Fig. 5: 3). Por su parte, los pocos fragmentos que presentan escisión, muestran decoraciones de gran personalidad, consistentes en una serie de motivos triangulares que, aunque en algunos ejemplos se nos muestran como elementos exclusivos, generalmente forman parte de sintaxis decorativas más complejas. Respecto a las decoraciones plásticas, observamos como aparecen una serie de piezas decoradas a base de cordones aplicados que exponen en todas las ocasiones un carácter múltiple y algún tipo de impresión

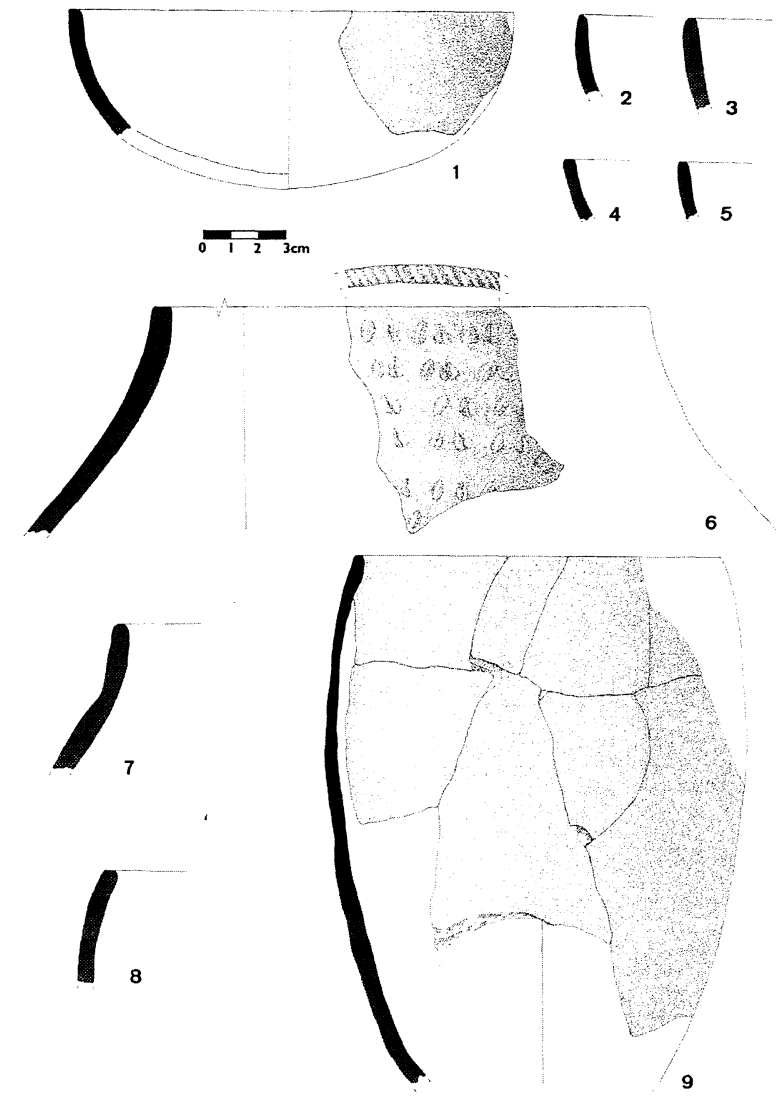

Fig. 4. Elementos cerámicos exhumados en la cueva de El Mirador.

sobre su superficie (Fig. 5: 7). Dentro de los elementos sobresalientes del perfil observamos también la presencia de un botón aplicado y de un pequeño pezón resaltado, situados en el cuello y borde de la pieza respectivamente (Fig. 5: 1).

Los elementos realizados para facilitar la sujeción de la pieza son escasos: hemos identificado un asa de sección en cinta, aislada del perfil al que pertenecía, y el arranque de otro asa de las mismas características situado sobre la carena de uno de los recipientes (Fig. 5: 5).

Por todo lo expuesto anteriormente, y en consonancia con el marco cronológico que indican las dataciones de C14, los materiales cerámicos de los conjuntos MIR3 y MIR4 de la cueva de El Mirador pertenecen a la Edad del Bronce. Este hecho viene apoyado por la presencia entre el material cerámico de las tazas carenadas, características de este periodo. El resto de formas identificadas no desdicen en absoluto la cronología apuntada, pudiendo rastrear todo el conjunto en multitud de yacimientos que en el norte y centro de la Península Ibérica 

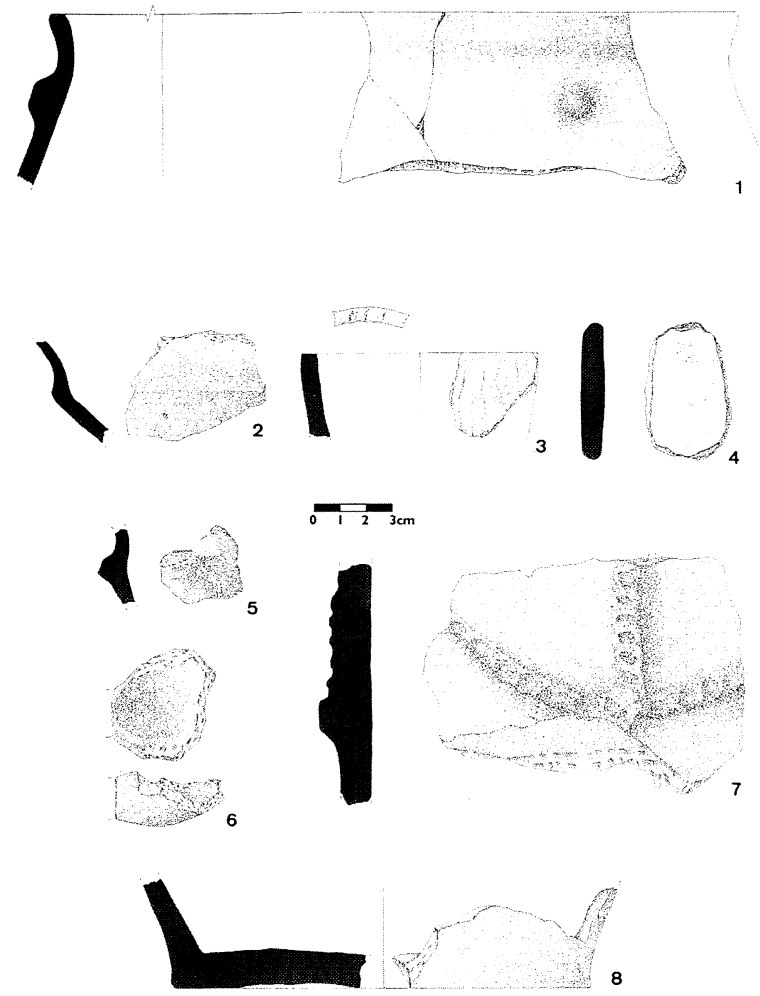

Fig. 5. Elementos cerámicos exhumados en la cueva de El Mirador.

poseen una adscripción semejante. Dentro de este ámbito se sitúan los yacimientos de la Edad del Bronce del sur del Sistema Ibérico Turolense cuyo material ha sido analizado por Picazo Millán (1993). En el estudio morfométrico que este autor realiza sobre los recipientes carenados, concluye que en los primeros momentos de la Edad del Bronce este tipo de perfiles presenta una clara tendencia entrante, mientras que a medida que avanza el tiempo, ya a partir del Bronce Medio, esta tendencia se va invirtiendo y comienzan a proliferar los perfiles carenados con un cuerpo superior claramente abierto o exvasado. En palabras de este investigador, los resultados son extrapolables a otros territorios peninsulares, advirtiéndose entre las piezas carenadas de El Mirador una mayor abertura en las pertenecientes al conjunto MIR3. Sin embargo, la datación del techo de MIR4 se adentra en la última fase de la Edad del Bronce, donde son habituales -y podríamos decir que casi exclusivosotro tipo de recipientes que por su carácter sumamente abierto han sido merecedores del nombre de "vasos troncocónicos". Ninguna de las cerámicas de El Mirador puede ser incluida dentro de este apartado, por lo que creemos que el marco cronológico del material habría de situarse entre finales del Bronce Antiguo principios del Bronce Medio y el Bronce Tardío, esto es entre 3400 y 3150 BP aproximadamente, sin prolongación por tanto hasta los últimos momentos de esta etapa. Este hecho viene acreditado por la fecha de $3400 \pm 40 \mathrm{BP}$ de la base del conjunto MIR4, mientras que la datación de la muestra tomada de la parte superior de este mismo conjunto $-3040 \pm 40 \mathrm{BP}-$, se nos antoja quizá algo reciente para tal adscripción. No obstante, teniendo en cuenta el carácter meramente orientativo que deben tener este tipo de análisis, consideramos que tampoco se desliga de una forma ostensible del momento más moderno del conjunto, que en ningún caso alcanzaría la última fase de desarrollo de la Edad del Bronce (3). Yacimientos como Los Tolmos de Caracena (Jimeno y Fernández Moreno, 1991), El Balconcillo (La-Rosa, 1991), Arevalillo de Cega (Fernández-Posse, 1981), Moncín (Harrison et al., 1994), Los Husos (Apellániz, 1974), o la propia Cueva Mayor de Atapuerca (Clark, 1979), presentan entre sus materiales del Bronce Medio/Tardío unas formas en todo semejantes a las de El Mirador, con la comparecencia además de cuantiosas piezas con cordones aplicados que no hacen sino apoyar esta idea. Asimismo, en estas últimas estaciones situadas en la franja más septentrional, nos encontramos también con diversas cerámicas decoradas a base de uñadas que ponen en relación nuestro material con la zona más norteña de la Península Ibérica, dado que a medida que nos acercamos al valle del Duero este tipo de ornamentaciones va desapareciendo. Este es un hecho que ya venía siendo advertido por Rodríguez Marcos (e.p.) para el sector norte y centro de la provincia de Burgos en relación con lo que sucede en la ribera del Duero burgalesa. Sin embargo, y a pesar de que todos los elementos apuntan a un marco cronológico situado a partir del Bronce Medio, llama la atención la ausencia total de las clásicas decoraciones que a partir de este momento se vienen efectuando sobre las cerámicas del Bronce Medio en adelante, y que han dado lugar a la creación de un horizonte cultural con personalidad propia conocido con el nombre de Cogotas I. Dicho horizonte, que por cronología debería verse repre-

(3) Moral del Hoyo, Sergio (2001): La cueva de El Mirador: un yacimiento de la edad del Bronce en el sur de la Sierra de Atapuerca. Dpto. de Ciencias Históricas y Geografía. Facultad de Humanidades y Educación. Universidad de Burgos. Trabajo de Investigación inédito. 
sentado en su momento de formación o Protocogotas, no aparece reflejado en ninguna de las piezas recuperadas en El Mirador, lo que a nuestro modo de ver, lejos de deberse a una deficiencia de la excavación -escaso número de piezas recuperado o pequeña superficie excavada-, responde a otro tipo de cuestiones más complejas que excederían ampliamente el carácter preliminar de este artículo.

\section{ELEMENTOS METÁLICOS}

Tan sólo se ha recuperado un elemento metálico, perteneciente al conjunto MIR3. Se trata de un hacha de bronce de $92 \times 45 \times 16 \mathrm{~mm}$ de dimensiones máximas y un peso de 160 gr. Tipológicamente se corresponde con un hacha de rebordes ligeros, cuyo cuerpo, de morfología horizontal de tendencia rectangular, sólo la pierde a medida que se aproxima al filo. Sus flancos son ligeramente cóncavos y se abren en un ángulo de unos $35^{\circ}$ en la parte distal para delimitar un amplio filo de delineación convexa.

Estudios recientes consideran que los primeros momentos metalúrgicos de la submeseta norte se pueden dividir en dos fases bien diferenciadas: el Calcolítico-Bronce Antiguo, dado que ambos períodos participan de una misma dinámica en cuanto a los tipos metálicos y a las técnicas metalúrgicas, y el Bronce Medio (Delibes et al., 1999).

El Bronce Medio representa un momento de marcada personalidad en el contexto arqueológico de la submeseta norte. En el ámbito metalúrgico y desde una perspectiva meramente tipológica, a pesar de la continuación de algunos tipos del momento anterior, se caracteriza por la presencia de una serie de novedades importantes como son las primeras aleaciones de $\mathrm{Cu}$-Sn y la introducción de tipos extraños al área: espadas de tipo argárico, estoques y palstave (Delibes et al., 1999), aunque de manera muy escasa.

Tipológicamente, y a falta de otros análisis sobre la pieza de El Mirador (metalografías y análisis químico) que nos informen de aspectos tecnológicos -aunque sabemos de la presencia de $\mathrm{Sn}$ mediante un primer análisis con MER-cabe situarla dentro del dominio de las denominadas hachas de rebordes.

Estas hachas hacen su aparición en contexto del Bronce europeo a finales del Bronce Antiguo con unos rebordes ligeros, si bien su uso se generaliza

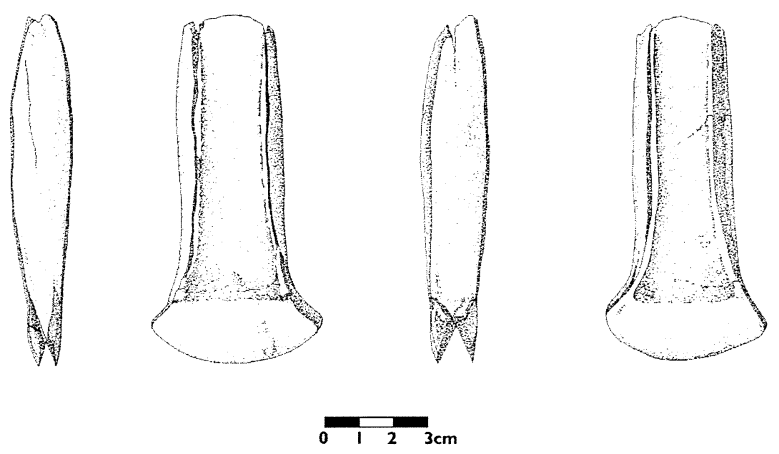

Fig. 6. Hacha de rebordes perteneciente al conjunto MIR3.

durante el Bronce Medio. Se trata de una pieza con pocos paralelos en la submeseta norte aunque, ciertamente, no es una excepción en el contexto arqueológico de la Península Ibérica durante el horizonte del Bronce Medio-Bronce Final (4).

El reciente estudio de los bronces del Bronce Medio de la colección Fontaneda (Delibes et al., 1999: 165-173) incide en el proceso de continuismo en el ambiente metalúrgico peninsular. Se considera que existe una homogeneidad cultural en el interior de la Meseta sobre la cual se introducen ciertos tipos extrapeninsulares, como la introducción de hachas de rebordes por ambos lados de los Pirineos y la introducción de ciertos tipos atlánticos desde el noroeste peninsular. Este proceso nos ayuda a considerar el Bronce Medio como un período de escasa renovación en los usos metálicos y la aparición de comportamientos técnicos de larga tradición. Aunque este no es un horizonte ajeno a la introducción de nuevos aspectos formales en los tipos, tales como los filos extendidos y la aparición

(4) En la provincia de Burgos se conocen tres ejemplares de morfología parecida, aunque ninguno de ellos tiene su procedencia asegurada. Posiblemente el ejemplar de Retuerta sea el más parecido, puesto que presenta ciertas características europeas en la tipología y la composición (Delibes y Esparza, 1985: 156). No obstante, se incluye dentro de las hachas planas burgalesas. Monteagudo (1977) recoge otros dos ejemplares, aunque con ciertas dudas sobre su contexto. En áreas vecinas se conoce de estas hachas en Castrocontrigo, provincia de León (Monteagudo, 1977: fig. 45,765$)$ y tres ejemplares más en la provincia de Salamanca (Monteagudo, 1977: fig. 47, 782-784) aunque en este caso los parecidos son menores. En las regiones circundantes más próximas al dominio meseteño se encuentran ejemplares de este tipo en El Pendo y Revilla de Camargo en Cantabria (Arias y Armendáriz, 1998), en Santianes (Monteagudo, 1977: fig. 45, 764), Cangas de Narcea (Monteagudo, 1977: fig. 46, 775) y otra depositada en el Museo provincial de Oviedo (Blas, 1999) en tierras asturianas, y ya en la provincia de Guipúzcoa, destaca la hallada en la Cueva de Zabalaitz (Apellaniz, 1973: fig. 99 bis). Más alejados del ámbito meseteño encontramos los ejemplares hallados en Cataluña (Martín Cólliga et al., 1999) y en Aragón (Rodríguez, 1999). 
de rebordes, estos elementos aparecen en la Meseta con mayor frecuencia en contextos del Bronce Tardío (Blas, 1999; Rodríguez, 1999).

Nos inclinamos a pensar que el hacha aparecida en el conjunto MIR3 puede tratarse de una perduración de este tipo de hachas más allá de su momento de máxima distribución en territorio europeo. Este es un hecho que no resulta ajeno a la dinámica arqueológica de la zona, puesto que la metalurgia del horizonte del Bronce Pleno/Tardío se caracteriza por su arcaísmo y la aparición de modelos tipológicamente mucho más antiguos que en otras zonas del occidente europeo (Delibes et al., 1999). Las hachas halladas en territorio peninsular pertenecen a ejemplares de rebordes largos y paralelos, semejantes a las de tipo Médocaine. Se trata de un tipo de hacha abundante en territorio francés fuera de su área original, como en: Gascogne gersoise (Cantet, 1991) y Saint Marcel à Bidon (Vital, 1988: fig. 4., 1-2). Coffyn las clasifica en tres tipos distintos a partir de la longitud de las mismas (Cantet, 1991: 194). Así pues, el hacha aparecida en El Mirador puede asociarse, con ligeras variantes en cuanto al tamaño, con el Tipo III en virtud de las similitudes con los paralelos anteriormente citados, para los que se propone una cronología aproximada del Bronce C o Reciente (Gómez de Soto, 1995; 82).

\section{CONCLUSIONES}

La información aportada hasta el momento por el sondeo realizado en la cueva de El Mirador nos permite realizar un esbozo de las actividades llevadas a cabo en esta cavidad durante la Edad del Bronce.

Con anterioridad a las ocupaciones de MIR4 se registra un periodo de escasa o nula actividad antrópica; al menos en la zona interesada por el sondeo. Este lapso de tiempo se corresponde con la deposición del conjunto MIR5, que cronológicamente debe situarse entre $4780 \pm 40$ y $3400 \pm 40$ años BP, dataciones realizadas sobre muestras de carbón vegetal procedentes respectivamente de MIR6 y de la base del conjunto MIR4. El conjunto MIR5 es producto de procesos de sedimentación naturales, básicamente aportes gravitacionales.

Las primeras ocupaciones de la Edad del Bronce se documentan en el conjunto MIR4. En este momento, la información paleobotánica disponible nos informa de la presencia en el entorno de una formación de carácter mixto, con especies de carác- ter mesófilo como el cornejo, el fresno, el avellano y las rosáceas, y con elementos perennifolios, de Quercus sp. perennifolio. Además, cabe señalar la presencia de taxones que crecen en ambientes de ribera como el sauce y el saúco, procedentes probablemente de las márgenes del cercano río Arlanzón.

El estudio de los caracteres del sedimento de MIR4 indica, sin ninguna duda, que la zona afectada por el sondeo fue utilizada reiteradamente durante el Bronce Medio como redil para el ganado. $\mathrm{La}$ formación de este conjunto es producto básicamente de la acumulación de excrementos de origen animal y de paja, y posterior quema de estos residuos en el mismo lugar de deposición. El hecho de que se hayan documentado episodios sucesivos de deposición y quema de niveles de corral indica que esta práctica se llevaba a cabo de forma periódica.

Basándonos en la información obtenida del registro faunístico, el rebaño estaría compuesto principalmente por ovejas y cabras, mientras que el ganado porcino, vacuno y caballar completaría la cabaña ganadera, sin alcanzar en ningún caso porcentajes importantes. Como es lógico, la alimentación del ganado se llevaría a cabo mediante el pastoreo y el ramoneo. No obstante, disponemos de ciertos indicios que apuntan hacia un consumo de forraje también en el interior de la cavidad. La presencia de pseudomorfos de fibras vegetales calcinadas, muy probablemente paja, en los niveles de corral quemados pueden representar restos de la alimentación del rebaño o de las camas del ganado.

Cabe señalar también, entre las especies domésticas identificadas en el yacimiento, la presencia del perro, que sería el responsable de las marcas de mordedura documentadas en algunos de los restos óseos.

Sin embargo, el registro arqueológico de MIR4 nos indica que la ganadería no era la única actividad productiva de estas comunidades. La ya mencionada presencia de paja, granos de cereal y dientes de hoz señalan la realización de prácticas agrícolas en una línea básicamente cerealista.

Los recursos aportados por la ganadería y la agricultura se complementan con la caza de especies salvajes como el jabalí, el ciervo y el conejo, y probablemente con la recolección de productos vegetales, ya sea destinados al consumo humano o a la alimentación del rebaño.

Pese a que, en el sondeo, el sedimento del conjunto MIR4 está formado básicamente por residuos derivados del uso de ese espacio como redil, no es este el único uso que se dio a la cavidad. La presen-

T. P., 59, n. ${ }^{\circ} 1,2002$ 
cia en el registro de artefactos que podemos relacionar con actividades de tipo doméstico, así como el hecho que muchos de los huesos de animales recuperados presenten marcas de corte y fracturas que pueden relacionarse con su aprovechamiento alimenticio y con prácticas culinarias, hace pensar en una zona de hábitat que se situaría verosímilmente en otro lugar de la cueva.

En un contexto ocupacional de este tipo, buena parte del material arqueológico recuperado se interpreta como residuos de actividades domésticas que fueron arrojados al corral. No obstante, hay que tener en cuenta que de haberse llevado a cabo en este lugar actividades que pudieran generar asociaciones espaciales representativas, el intenso pisoteo y removilización de materiales derivados de la presencia del rebaño las habrían destruido.

En MIR3 los niveles de redil quemados periódicamente desaparecen para dar paso a una sedimentación mixta, con aportes gravitacionales de vertiente, y antrópicos, básicamente carbones y ceniza. Esta variación indica un cambio en la funcionalidad del espacio al menos de la zona donde se ubica el sondeo. Aparte de los caracteres del sedimento, el registro arqueológico de MIR3 es muy similar tanto en composición como en representación al de MIR4. Tan solo se observa un ligero descenso de la cabaña caballar y vacuna, una menor representación de los elementos directamente relacionados con la agricultura (sólo se han recuperado algunos granos de cereal carbonizados) y un cierto incremento en la variabilidad de la cultura material.

La inhumación de restos humanos óseos documentada en el sondeo, así como la ya conocida existencia de una inhumación colectiva en el laminador del extremo norte de la cueva, indican el uso de la cavidad con fines sepulcrales. No obstante, la información disponible en la actualidad no permite conocer si existe alguna relación entre ambas, ni definir su relación temporal con el resto de episodios documentados. En el caso de los restos óseos depositados en la fosa parece tratarse de una inhumación de tipo secundario realizada durante el Bronce Medio o el Bronce Tardío con restos pertenecientes a individuos del Bronce Antiguo.

\section{AGRADECIMIENTOS}

A Alfredo Pérez González por su colaboración en el trabajo de campo, especialmente en todos los aspectos relacionados con los sondeos geofísicos y mecánicos llevados a cabo en la cueva de El Mirador, así como por su tarea de coordinación del programa de dataciones radiométricas.

A J.A. Rodríguez Marcos por sus consejos en el apartado de cerámica. A Arturo Morales por la ayuda prestada en el estudio de los restos de fauna, así como para acceder a la colección comparativa del Laboratorio de Arqueozoología de la Universidad Autónoma de Madrid. Los dibujos de cerámica y del hacha metálica han sido realizados por L. Ibáñez.

La labor de investigación que desempeñan Ethel Allué y Josep M. ${ }^{a}$ Vergès en el marco del proyecto Autoecología Humana y Tecnología de los Pobladores Prehistóricos de la Sierra de Atapuerca (DIGICYT No. PB-96-1026-C03-02) es posible gracias a una beca de la Fundación Atapuerca.

También queremos agradecer a los vecinos de Ibeas de Juarros y de Atapuerca su apoyo constante y la ayuda prestada en determinados momentos de la excavación, encaminada a facilitar la realización de los trabajos de campo.

\section{BIBLIOGRAFÍA}

AKeret, Ö.; HaAs, J.N.; LeuZinger, U. y JACOMET, S. (1999): "Plant macrofossils and pollen in goat/sheep faeces from the Neolithic lake-shore settlement Arbon Bleiche 3, Switzerland". The Holocene 9(2): 175-182.

Altuna, J. (1986): "Economías prehistóricas cazadoras y ganaderas en el País Vasco y resto de la región cantábrica". Revista Internacional de los Estudios Vascos XXXI (3): 609-627.

ANGELuCCI, D.E. y Boschian, G. (e.p.): Preliminary remarks on the micromorphology of the Riparo Gaban (Trento, Italy) archaeological succession»". En L. Trombino (ed.): Proceedings of the Archaeological Micromorphology Working Group (Sondrio, December 2000). Quaderni di Geodinamica Alpina e Quaternaria. Università di Milano. Milano.

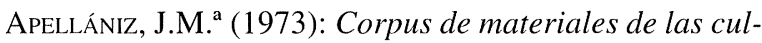
turas prehistóricas con cerámica de la población de cavernas del País Vasco Meridional. Suplemento a $\mathrm{Mu}$ nibe 1. San Sebastián.

- (1974): El grupo de Los Husos durante la prehistoria con cerámica. Estudios de Arqueología Alavesa 7. Vitoria.

Argant, J.; Heinz, C. y Brochier, J.L. (1991): "Pollens, Charbons de bois et sediments: L'action humaine et la végétation, cas de la grotte d'Antonnaire (Montmauren-Diois, Drôme)". Révue d'Archéométrie 15: 29-40.

Arias, P. y ARMENDÁRIZ, A. (1998): "Aproximación a la Edad del Bronce en la región cantábrica”. En R. Fábre- 
gas (ed.): A Idade do Bronce en Galicia: novas perspectivas. Cadernos do Seminario de Sargadelos 77. A Coruña: 47-80.

Armendáriz, A. y Etxeberría, F. (1983): "Las Cuevas Sepulcrales de la Edad del Bronce en Guipúzcoa". Munibe 35: 309-312

BADAL, E. (1992): "L'anthracologie préhistorique: à propos de certains problèmes méthodologiques". Bulletin de la société botanique de France. Actualités Botaniques 139 (2/3/4): 168-189.

- (1999): "El potencial pecuario de la vegetación mediterránea: las cuevas Redil”. II Congrés del Neolític a la Península Ibèrica (Valencia 1999). Saguntum Extra2: 69-75.

Barandiarán, J.M. (1952): "La Prehistoria en el Pirineo Vasco. Estado actual de su estudio". Actas del ${ }^{\text {er }}$ Congreso Internacional de Estudios Pirenaicos: 209-221. Zaragoza.

BERGADÀ, M.M. (1997): "Actividad antrópica registrada en algunas secuencias arqueológicas en cueva del Neolítico antiguo catalán a través del análisis micromorfológico". Trabajos de Prehistoria, 54 (2): 151-162.

Blanco, E.; Casado, M.A.; Costa, M.; Escribano, R.; GarCía, M.; Génova, M.; Gómez, A.; Gómez, F.; Moreno, J.C.; Morla, C.; Regato, P. y Sainz, H. (eds.) (1998): Los bosques ibéricos. Una interpretación geobotánica. Editorial Planeta. Madrid.

Blas, M.A. de (1999): “Asturias y Cantabria”. En G. Delibes e I. Montero (coord.): Las primeras etapas metalúrgicas en la Península Ibérica. II. Estudios regionales. Instituto Universitario Ortega y Gasset. Madrid: 42-62.

Blasco, A.; Edo, M.; Villalba, M.J.; Buxó, R.; Juan, J. y SAÑA, M. (1999): "Del cardial al postcardial en la cueva de Can Sadurní (Begues, Barcelona). Primeros datos sobre su secuencia estratigráfica, paleoeconómica y ambiental”. II Congrés del Neolític a la Península Ibèrica (Valencia 1999). Saguntum Extra-2: 59-67.

Bolaños, M.M. (1960): "Las plantas leñosas en la alimentación y pastoreo de la ganadería española". Montes 16 : 347-51.

Brochier, J.-E. (1983): "Bergeries et feux de bois néolithiques dans le Midi de la France. Caractérisation et incidence sur le raisonnement sédimentologique". Quartär 33-34: 119-135.

- (1988): "Sédimentologie, environnement et activites humaines du Néolithique aux temps historiques : Les sediments anthropiques de l'abri de Fontjuvenal". En AA.VV: Six millénaires d'historie de l'environnement: étude interdisciplinaire de l'abri sous roche de FontJuvénal (Conques sur L'Aude). Centre d'anthropologie des sociétés rurales. Tolouse: 20-30.

- (1995): Estudi geoarqueològic dels dipòsits holocens de la Balma de la Margineda: capes 1 a 6. En J. Guilaine y M. Martzluf (eds.): Les excavacions a la Balma de la Margineda (1979-1991). Edicions del Govern d'Andorra 1. Andorra: 56-90.
- (1996): "Feuilles ou fumiers? Observations sur le rôle des poussières sphérolithiques dans l'interpretation des dépôts archéologiques holocènes". Anthropozoologica 24: $19-30$

Brochier, J.E. y Claustre, F. (1994): "Le parcage des bovins et le problème des litières du Néolithique final à l'Âge du Bronze dans la Grotte de Bélesta". XXIVe Congrès Préhistorique de France. Habitats, économies et sociétés du Nord-Ouest méditerrannéen (Carcassonne 1994): 27-36.

Brochier, J.E.; Claustre, F. y Heinz, C. (1998): “Environmental impact of Neolithic and Bronze age farming in the eastern Pyrenees forelands, based on multidisciplinary investigations at La Caune de Bélesta (Bélesta Cave), near Perpignan, France". Vegetation History and Archaeobotany 7: 1-9.

Boschian, G. y Montagnari-Kokel, E. (2000): "Prehistoric shepherds and caves in the Trieste Karst (Northeastern Italy)". Geoarchaeology. An International Journal 15 (4): 331-371.

CANTET, J.P. (1991): "Les influences du Bronze Atlantique en Gascogne Gersoise". En C. Chevillot y A. Coffin (eds.): L'Age du Bronze Atlantique. Actes du 1er Coloque du Parc Archéologique de Beynac (Perigueux 1990): 193-202.

Carbonell, E.; Guilbaud, M. y Mora, R. (1983): "Utilización de la lógica analítica para el estudio de tecno-complejos a cantos tallados". Cahier Noir 1: 3-64.

Carbonell, E.; Mosquera, M.; Ollé, A.; Rodríguez, X.P.; SAla, R.; VAQUERO, M. y Vergès, J.M. (1992): "New elements of the Logical Analytic System". Cahier Noir 6: 1-61.

Clark, G.A. (1979): "Bronze and Iron archaeology on the Meseta del Norte (Province of Burgos, North-Central Spain)". The North Burgos Archaeological Survey. Arizona State University.

Courty, M.-A.; MacPhall, R. y Wattez, J. (1992): "Soil micromorphological indicators of pastoralism: with special reference to Arene Candide, Finale Ligure, Italy". En R. Maggi, R. Nisbet y G. Barker (eds.): Archeologia della pastorizia nell'Europa meridionale. Rivista di Studi Liguri, 56+57, 2 (57): 127-150.

Chabal, L.; Fabre, L.; Terral, J.F. y Théry-Parisot, I. (1999): L'anthracologie. La Botanique. A. Ferdière. Ed. Errance. Paris: 43-104.

Delibes, G. y Esparza Arroyo, A. (1985): "Neolítico y Edad del Bronce". Historia de Burgos I. Edad Antigua. Burgos: 117-177.

Delibes, G.; Fernández Manzano, J.; Fontaneda, E. y Rovira, S. (1999): Metalurgia de la Edad del Bronce en el piedemonte meridional de la Cordillera Cantábrica. La colección Fontaneda. Monografías, 3. Zamora.

Delibes, G.; Fernández Manzano, J. y Herrán, J.I. (1999): "Submeseta Norte". En G. Delibes e I. Montero (coord.): Las primeras etapas metalúrgicas en la Pe-

T. P., 59, n. ${ }^{\circ} 1,2002$ 
nínsula Ibérica. II. Estudios regionales. Instituto Universitario Ortega y Gasset. Madrid: 63-94.

Etxeberría, F. (1990): "Los estudios de Paleopatología en el País Vasco". En Homenaje a D. José Miguel de Barandiarán. Munibe 42: 221-227.

FERnÁndez Posse, M. ${ }^{a} D$. (1981): "La cueva de Arevalillo de Cega (Segovia)". Noticiario Arqueológico Hispánico 12: 45-84.

García, M. y Carrasco, J. (1981): “Cráneo-copa eneolítico de la Cueva de Carigüela de Piñar (Granada)". Zephyrus XXXII-XXXIII: 121-131.

GómEZ DE Soto, J. (1995): Le Bronze Moyen en Occident. La Culture des Duffaits et la Civilisation des Tumulus. L'Âge du Bronze en France 5. Paris.

HAAS, J.N.; KARG, S. y RASMUSSEN, P. (1998): "Beech leaves and twigs used as winter fodder: examples from historic and prehistoric times". Environmental Archaeology 1: 81-86.

Halstead, P. y Tierney, J. (1998): "Leafy hay: an ethnoarchaeological study in NW Greece". Environmental Archaeology 1: 71-80.

Harrison, R.J.; Moreno López, G.C. y LegGe, A.J. (1994): Moncín: Un poblado de la Edad del Bronce (Borja, Zaragoza). Colección Arqueología, 16. Gobierno de Aragón. Zaragoza.

Heinz, C. (1990): "Dynamique des végétations holocénes en mediterrannée nord-occidentale d'après l'anthracoanalyse de sites préhistoriques methodologie and paleoécologie". Paleobiologie Continentale XVI: 212.

Jacquiot, C.; Trenard, Y. y Hidrol, D. (1973): Atlas d'anatomie des bois des angiospermes. Texte. Centre technique du bois 175. París.

Jimeno, A.; Fernández Moreno, J.J. (1991): Los Tolmos de Caracena (Soria). Campañas de 1981 y 1982. Aportación al Bronce Medio de la Meseta. Excavaciones Arqueológicas en España 161. Ministerio de Cultura. Madrid.

KARG, S. (1998): "Winter-and spring-foddering of sheep/ goat in the Bronze Age site of Fiavè-Carera, Northern Italy". Environmental Archaeology 1: 87-94.

LA-Rosa, R. de (1991): "El Balconcillo del cañón del río Lobos. Un yacimiento del Bronce Pleno en el oriente de la Meseta Norte". Soria Arqueológica 1: 69-86.

Macphail, R.; Courty, M.-A.; Hather, J. y Wattez, J. (1997): "The soil micromorphological evidence of domestic occupation and stabling activities". En R. Maggi (ed.): Arene Candide: A Functional and Environmental Assessment of the Holocene Sequence (Excavations Bernabo Brea-Cardini 1940-50). Memorie dell'Istituto Italiano di Paleontologia Umana 5: 53-88.

MAGGI, R. (ed.) (1997): Arene Candide: A Functional and Environmental Assessment of the Holocene Sequence (Excavations Bernabo Brea-Cardini 1940-50). Memorie dell'Istituto Italiano di Paleontologia Umana 5.

Martín Cólliga, A.; Gallart, J.; Rovira Hortalà, C. y Mata-Perelló, J.M. (1999): "Nordeste”. En G. Deli- bes e I. Montero (coord.): Las primeras etapas metalúrgicas en la Península Ibérica. II. Estudios regionales. Instituto Universitario Ortega y Gasset. Madrid: 115177.

Monteagudo, L. (1977): Die Beile auf der Iberischen Halbinsen. Prahistorische Bronzefunde, Agteilung IX, 6 , Band, C. H. Beckische Verlagsbuchhandlurg, Munich.

Obermaier, H. (1925): El Hombre Fósil. Memorias de la Comisión de Investigaciones Paleontológicas y Prehistóricas. Madrid.

Osaba, B. y Ruiz de ERenchun, B. (1978): "Las cuevas prehistóricas burgalesas en relación con el Museo Arqueológico". Kaite I. Grupo Espeleológico Edelweis. Caja de Ahorros Municipal de Burgos: 71-82.

Palomino, A.L. y Rodríguez Marcos, J.A. (1994): "El yacimiento arqueológico de Las Empedradas: un enclave del Bronce Medio en la Ribera del Duero burgalesa". Numantia. Arqueología en Castilla y León 5: 59-71.

Pérez Rodríguez, F.J.; Misiego, J.C.; Sanz, F.J.; Marcos, G.J.; Martín Carbajo, M.A. y Fernández Giménez, J.M. (1994): "La Huelga. Un interesante yacimiento de la Edad del Bronce en el centro de la Cuenca del Duero (Dueñas, Palencia)". Numantia. Arqueología en Castilla y León 5: 11-32.

PiCAZo Millán, J.V. (1993): La Edad del Bronce en el Sur del Sistema Ibérico Turolense I: Los materiales cerámicos. SAET. Colegio Universitario de Teruel. Teruel.

RASMUSSEN, P. (1989): «Leaf-foddering of livestock in the Neolithic: archaeobotanical evidence from Weir, Switzerland». Journal Danish Archaeology 8: 51-71.

- (1993): «Analysis of goat/sheep faeces from Egolzwill 3, Switzerland: evidence for branch and twig foddering of livestock in the Neolithic». Journal of Archaeological Science 20 (5): 479-502.

Rodanés, J.M. (1987): La Industria Ósea Prehistórica en el Valle del Ebro. Neolítico-Edad del Bronce. Colección Arqueología y Paleontología 4. Diputación General de Aragón. Zaragoza.

Rodríguez MARCos, J.A. (e.p.): "Estado actual de la investigación del Calcolítico y la Edad del Bronce en la Provincia de Burgos". Actas del I Congreso de Arqueología Burgalesa (Burgos 1998).

Rodríguez MArcos, J.A. y Abarquero, F.J. (1994): “Intervención arqueológica en el yacimiento de la Edad del Bronce de El Cementerio-El Prado, Quintanilla de Onésimo (Valladolid)". Numantia. Arqueología en Castilla y León 5: 33-57.

Rodríguez Marcos, J.A. y Palomino, A.L. (1997): “Un asentamiento castreño del Bronce Antiguo en la Cuenca del Duero: El Pico Romero en Santa Cruz de la Salceda (Burgos)". En R. de Balbín y P. Bueno (eds.): II Congreso de Arqueología Peninsular. II- Neolítico, Calcolítico y Bronce. Fundación Rei Afonso Henriques. Zamora: 579-590.

Rodríguez, Ma.J. (1999): “Aragón”. En G. Delibes e I. Montero (coord.): Las primeras etapas metalúrgicas en 
la Península Ibérica. II. Estudios regionales. Instituto Universitario Ortega y Gasset. Madrid: 95-113.

SCHWEINGRUBER, F.H. (1990): Anatomie europäischer Hölzer ein Atlas zur Bestimmung europäischer Baum-, Strauch- und Zwergstrauchhölzer Anatomy of European woods an atlas for the identification of European trees shrubs and dwarf shrubs. Verlag Paul Haupt. Stuttgart.
VITAL, J. (1988): "La Dynamique du Bronze Moyen dans la Vallée du Rhône: Nature et Impact des courants culturels exogènes. 113 Congrès national des Sociétés savantes, Pré-Protohistoire, Dinamique du Bronze Moyen (Strasbourg 1988): 305-329.

WATERBolk, H.T. (1971): "Working with radiocarbon dates". Proceedings Prehistoric Society 37: 15-33.

T. P., 59, n. ${ }^{\circ} 1,2002$ 